\title{
A importância da metodologia interdisciplinar: uma abordagem geográfica
}

Este trabalho é uma reflexão inicial sobre a ideia de interdisciplinaridade e sua correlação com uma possível transição na ordenação das áreas de conhecimento científico. Nesta perspectiva, a Geografia serve de pano de fundo para uma crítica ao movimento de especialização e fragmentação teórica e metodológica das disciplinas e, para discutir o projeto de interação de saberes. Em suma, aborda o conhecimento geográfico através de suas contradições internas, sua relação com outras disciplinas e com a complexidade da realidade global.

Palavras-chave: Interdisciplinaridade; Geografia; Complexidade.

\section{The importance of interdisciplinary methodology: a geographical approach}

This work is an initial reflection on the idea of interdisciplinarity and its correlation with a possible transition in the ordering of areas of scientific knowledge. In this perspective, Geography serves as a background for a critique of the movement of theoretical and methodological specialization and fragmentation of the disciplines, and for discussing the project of knowledge interaction. In short, it approaches geographic knowledge through its internal contradictions, its relationship with other disciplines and with the complexity of global reality.

Keywords: Interdisciplinarity; Geography; Complexity.

Topic: Ensino Superior, Pesquisa e Extensão

Reviewed anonymously in the process of blind peer.
Received: 22/01/2021

Approved: 19/05/2021

Charles Benedito Gemaque Souza

Universidade Federal do Pará, Brasil

http://lattes.cnpq.br/6419817700801648

http://orcid.org/0000-0002-5966-9556

gemaquec@ufpa.br

Referencing this:

SOUZA, C. B. G.. A importância da metodologia interdisciplinar: uma abordagem geográfica. Humanum Sciences, v.3, n.1, p.14-22, 2021. DOI: http://doi.org/10.6008/CBPC2674-6654.2021.001.0002 


\section{INTRODUÇÃO}

Entender o mundo atual tornou-se um grande desafio para o conhecimento científico devido à complexidade e ao caos que predominam nas dinâmicas, nos usos e conteúdos socioambientais. Diante disso, as disciplinas que insistirem em posturas simplistas, ultrapassadas e/ou fechadas podem não explicar adequadamente os fenômenos dessa realidade total que lhes cabem.

A Geografia é na essência uma ciência multifacetada com variações epistêmicas e na organização acadêmica, tanto que na Universidade Federal do Pará, por exemplo, faz parte do rol das Ciências Humanas, enquanto na Universidade Federal do Rio de Janeiro, por outro lado, é considerada uma disciplina da área física. Paradoxalmente, conforme Santos (1996), o pensamento geográfico é um dos mais resistentes às mudanças qualitativas nos conjuntos de métodos científicos ocorridos nas últimas décadas.

Tal constatação nos remete a uma discussão sobre elementos da epistemologia da Geografia contemporânea, inicialmente é preciso discernir sobre as controversas que envolvem o desenvolvimento teórico e conceitual que consolidou a Geografia como uma disciplina especializada e autônoma.

Posteriormente, é preciso a partir de uma avaliação das interações entre os paradigmas das ciências naturais e das ciências sociais, analisar as teorias que predominam no arcabouço do pensamento geográfico atual. Para enfim, mostrar como a ideia de interdisciplinaridade vem ganhando força e consistência metodológica, tornando-se uma alternativa válida de resolução de problemas complexos e possibilitar uma integração de saberes no interior do objeto de estudo da Geografia.

\section{DISCUSSÃO TEÓRICA}

\section{O processo de construção de uma epistemologia disciplinar}

A Geografia é usualmente definida como um saber que problematiza os fenômenos que se manifesta na superfície terrestre, tal conceito se revela tão abrangente quanto impreciso. Logo, a afirmação do pensamento geográfico no rol das abordagens científicas de fato passa por uma melhor definição de sua matriz disciplinar.

A organização disciplinar foi instituída nas universidades modernas no século XIX, anteriormente o conhecimento era "categórico" dividindo-se em sete artes liberais: lógica, gramática e retórica (trivium); aritmética, geometria, astronomia e música (quadrivium). Para Klein (1990) a concepção de disciplina começou a ser utilizado em três áreas: para teologia e artes em Paris; nas leis em Bolonha; e para medicina.

A conotação de disciplinaridade é um produto que tem ligação com várias forças emergentes na época: a evolução da ciência natural moderna, a "cientificação" geral do conhecimento, a revolução industrial, o avanço tecnológico e a reforma agrária na Europa. Desta maneira, a demanda da indústria por especialistas, bem como a exigência dos estudantes por essas disciplinas reforçou essa nova tendência.

Neste contexto, a Geografia deixa de ser um saber "oficial" ${ }^{1}$ para se tornar um saber científico, 
embora todo o seu discurso inicial fizesse parte de uma "batalha" ideológica entre franceses e alemãs. Para Kant (1724-1804) o conhecimento geográfico era um saber empírico e sintético, ou seja, baseava-se na descrição e na composição dos conhecimentos já produzidos sobre a natureza. Desta forma, a filosofia kantiana foi responsável pela inserção da Geografia (física) na grade curricular da universidade de Koenigsberg (Alemanha) em 1756.

A escola alemã também foi responsável pelo surgimento da concepção científica da Geografia moderna. Autores como Humboldt, Ritter e Ratzel consolidam e sistematizam o conhecimento geográfico que era produzido e ensinado no final do século XIX (MOREIRA, 1998). Em consequência, a ideia de descrição e síntese da natureza permaneceu majoritária na análise geográfica por muito tempo.

Todavia, existem outras formas de pensar a Geografia, para alguns autores a paisagem seria o elemento central, neste caso os aspectos visíveis de real seria o fenômeno a ser explicado. Entre as variações desta proposta podemos citar a acepção que busca nas inter-relações das paisagens coexistentes um estudo das funções de cada elemento observado e assim individualizar e compreender uma determinada área da superfície terrestre.

Outros autores preferem argumentar que o saber geográfico é aquele que examina as diferenciações entre as áreas físicas através de modelos físicos e de informações obtidos. Para Moraes (1997) tal perspectiva foi uma das primeiras que propuseram uma análise de caráter "teorético" mais geral e quantitativo dentre as matrizes disciplinares apresentadas para a Geografia até a metade do século passado.

Já nos meados dos anos 60, o encontro do ideário materialista com a preocupação ambientalista deu início a uma epistemologia ambiental que trouxe um primeiro esboço de integração de saberes no pensamento geográfico. $\mathrm{O}$ espaço passa a ser visto como um substrato material e imaterial passível de ser explicado pelos geógrafos.

Nestes termos, a filosofia tornou-se a grande parceria da chamada geografia crítica, trazendo aspectos das estruturas sociais e da objetividade. Autores como Harvey e Castells foram alguns dos precursores, oferecendo visões teórico-metodológicas claramente decisivos para a conformação de uma abordagem dialética no pensamento geográfico.

A partir dessa percepção, a Geografia passou a ser vista como o estudo que trata das relações entre o homem e o meio, sendo sua especialidade lhe dá com os vínculos entre os dois domínios: sociedade e natureza. Moraes (1997) argumenta que tal situação tornaria o saber geográfico uma disciplina de contato permanente entre as ciências naturais e as ciências humanas.

Entretanto, Santos (1996) mostra que desde a fundamentação da Geografia científica esta não conseguiu construir um conjunto de princípios, leis e métodos baseados em um sistema comum e coerente internamente. Assim, os avanços teóricos dependiam de conceitos e categorias buscados em áreas afins (filosofia, economia e ecologia) do que da sua própria área de conhecimento.

Na prática isto repercutiu negativamente no pensamento geográfico, criando uma dicotomia entre a área física e a humana. De um lado, existe uma Geografia que toma a ação do meio no homem e na sociedade como algo peremptório para entendemos os fenômenos geográficos, enquanto por outro, a ideia de que 
ação do homem que influência o meio é o que prevalece.

Em resumo, o debate atual no interior da epistemologia geográfica busca um ponto de equilíbrio entre essas duas vertentes. De qualquer forma, é possível afirmar que a expressão mais adequada para definir como sua matriz disciplinar é que está trabalha com fenômenos naturais e sociais concomitantemente. A questão é que a geografia abarca um conjunto de teorias, leis e princípios diversificados que não podem se restringir as velhas concepções segmentadas do saber científico.

\section{Aspectos paradigmáticos da Geografia}

A ideia de paradigma, na acepção de Kuhn (1982) é formada por praticantes de uma especialidade científica autônoma que teria, a princípio, um objeto de estudo próprio, além de ser formado basicamente a partir de um currículo disciplinar comum. Em consequência, cada disciplina deve ter um conjunto de métodos condizentes com o seu objeto de estudo.

Contudo, isso não significa que cada disciplina seja isolada, no sentido de não buscar nas outras disciplinas atribuições que possam contribuir para as resoluções de problemas do seu objeto de estudo. Bachelard (1972) ensina que o real é único, logo mesmo que cada disciplina tenha uma visão particular dessa realidade, está faz parte de um todo complexo e único. Nesse caso, a autonomia paradigmática não significa independência ou separação de uma parte do todo.

Nesta direção, é preciso atentar para que a escolha do método de raciocínio de uma determinada realidade social esteja adequada ao conjunto de técnicas de pesquisa utilizadas pelo geógrafo. Bourdieu et al. (1999) afirma que há uma impossibilidade de que os fenômenos e fatos sociais sejam explicados desassociados das suas aplicações empíricas, pois mesmo sendo possível realizar, existe uma relação entre a definição do problema e a metodologia que repercute diretamente na obtenção do conhecimento científico.

Nesta acepção, o enfoque ambientalista e o enfoque humanista da Geografia acabaram se distanciando, de acordo com Claval (2004) enquanto os geógrafos físicos destacavam o ponto de vista sistêmico e quantitativo, os humanistas apoiavam-se cada vez mais na subjetividade e na pesquisa qualitativa. Reproduzindo, em determinados aspectos, de forma micro os debates sobre o que é saber científico ou não.

Tal questão envolve a teoria controvérsia de que para legitimar as ciências sociais seria necessária uma adaptação (submissão) de conceitos, princípios e/ou métodos específicos das áreas físicas e biológicas. Cohen (1994) mostra como exemplo o caso da chamada economia marginalista (Neoclássica) do final do século XIX e início do XX. Que escolheu a física como parâmetro, outro exemplo era a sociologia de Durkhein e Spencer que emulava a biologia.

Mais recentemente, as ciências sociais buscam referências no chamado "paradigma da complexidade", uma abordagem teórica que engloba diversas concepções tais como: a termodinâmica; a sinergética; e a teoria do caos. Conforme Souza (1995) discerne, houve autores que defenderam uma transposição direta dos esquemas analíticos destas teorias "naturais" para serem aplicados nas disciplinas "sociais". 
Desta forma, a analogia tornou-se uma maneira de adaptar uma concepção estranha à comunidade científica, ou seja, na impossibilidade de testar a veracidade era compensada pelo uso de afinidades em relação a outras experiências cientificamente comprovadas. Segundo Cohen (1994) a falta de correlação aparente entre essas teorias, criou dificuldades de entendimento, e até mesmo de coerência, dentro de certos tópicos levantados, ademais gerou várias interpretações equivocadas da concepção original.

Por outro lado, essas correlações científicas também fortaleceram determinadas visões transdisciplinares, como o da filosofia marxista. Nas palavras de Diniz Filho (2004) a assimilação intensa do marxismo foi o que caracterizou a Geografia nos aspectos teóricos, metodológicos e ideológicos a partir de 1970. Porém, houve diferencias significativas nas formas de apropriação, dependendo da origem, da instituição, da área (física ou humana) e até mesmo, interpretações particulares de alguns geógrafos ou de outros cientistas.

O problema é que na maioria das vezes essas analogias foram feitas à custa de grandes simplificações ou de leituras dogmáticas de determinadas teorias gerais. Com efeito, houve uma crescente insatisfação com os rumos tomados pela Geografia como uma ciência disciplinar, daí a atual tendência de mudança de rumo epistemológico de autores como Harvey e Castells.

Todavia, é preciso raciocinar pela ótica da permanência de um paradigma disciplinar conservador que por consequência impõe uma metodologia reducionista e fragmentada dentro de realidades socioambientais interligadas. Logo, a Geografia deve está integrada ao que Morin (2002) aponta como a verdadeira noção de complexidade científica, aquela onde a percepção fundamental é ultrapassar barreiras, criar um olhar extracurricular, embora isso não signifique uma ação migratória indiscriminada.

A capacidade de destacar alguns conceitos, princípios e métodos de disciplinas afins ou até mesmo de outras áreas de conhecimento é uma condição para que essa transposição contribua efetivamente para fortalecer o conhecimento do objeto de estudo geográfico. Tal possibilidade torna-se válida no momento que permite uma articulação e, sobretudo, uma relativização dessas teorias, ou seja, o desafio não é simplesmente abrir as fronteiras, e sim discernir as raízes do novo (SOUZA, 1995).

Em consequência, é preciso estabelecer pontos de convergência entre as disciplinas para que se possa ampliar o leque de possibilidades de se resolver problemas complexos dentro da pesquisa geográfica. Neste caso, assim como Matta (1993) fez uma reflexão sobre as possíveis contribuições de uma metodologia interdisciplinar na Antropologia, trata-se de examinar como os processos integrativos podem auxiliar nas resoluções de determinadas questões epistemológicas da Geografia.

Portanto, a trajetória particular da abordagem geográfica edificou um conhecimento disciplinar próprio que evidentemente não deve ser esquecido, no entanto o seu objeto de estudo não é um contexto social isolado, está subordinado a uma realidade geral que demanda, igualmente, uma abordagem holística.

\section{A metodologia interdisciplinar e a Geografia}

A ideia de interdisciplinaridade vem ganhando corpo como um método de pesquisa científica nos últimos anos. A partir de 1972 surgem os primeiros trabalhos publicados sobre o assunto reconhecidos pela 
comunidade acadêmica, porém, tal reconhecimento esbarrava em uma sequência de confusões criadas pela falta de unidade e síntese em torno do que é interdisciplinaridade ou não.

Para Klein (1990) a definição das atividades interdisciplinares reúne pesquisadores, educadores e profissionais, todos voltados para realizar cinco objetivos principais: 1) responder perguntas complexas; 2) dar conta de questões universais;3) explorar as relações disciplinares e profissionais; 4) resolver problemas que vão além do escopo de uma disciplina específica; 5) conseguir unidade de conhecimento em casos de uma escala limitada ou ampla demais.

Neste sentido, o projeto interdisciplinar trabalha com a ideia de interação do conhecimento científico fragmentado, o que não significa submissão, analogias e/ou homologias realizadas sem critérios e coerência interna, A interdisciplinaridade só funciona sob a regência dos interesses específicos de cada disciplina, deste modo, a interdisciplinaridade depende de rupturas de fronteiras.

A mobilidade tornou-se uma das características do conhecimento moderno, comparativamente, as pesquisas tradicionais que apontavam para uma análise simples do objeto de estudo. De acordo com Klein (1996) isto leva a algumas implicações básicas: primeiro, a necessidade de se proceder a um novo mapeamento do conhecimento, incluindo toda uma variedade de novos campos interdisciplinares, a partir de uma corrente de pensamento holístico. Dentro desse novo espaço de transição ou em transição, conceitos, princípios e métodos devem ser rotineiramente inquiridos, negociados e reconstruídos.

Outra implicação possível é a relação ente a metodologia disciplinar e interdisciplinar que pode despertar como uma oposição, um paradoxo ou uma dicotomia. Neste ponto, os modelos têm a tendência de promover práticas interdisciplinares por meio apenas de uma combinação de teorias existentes em torno de um assunto comum, minimizando as diversidades racionais, estratégicas, lógicas e formais contidas nas diferenças abordagens disciplinares.

É preciso reconhecer que mapear as atividades interdisciplinares não é uma tarefa fácil, devido as múltiplas fronteiras que ainda precisam ser ultrapassadas pela comunidade científica. Isto inclui demarcações entre o conhecimento acadêmico e intuitivo, ciência e senso comum bem como, entre as disciplinas e subdisciplinas, campos híbridos, setores da sociedade.

Segundo Klein (1996) nas ciências especialmente aquelas que têm um enfoque na sociedade, como no caso da Geografia, o pensamento holístico é também considerado filosófico (definição clássica), daí ainda ser considerado insuficientemente analítico e rigoroso metodologicamente. No entanto, o interesse crescente sobre questões complexas cria novas possibilidades teóricas e conceituais que propaga uma nova estratégia de interdisciplinaridade pelas diversas áreas de conhecimento.

No âmbito da Geografia, Gerardi et al. (2001) argumentam que o pensamento contemporâneo está em uma fase de revisões, criando expectativas, contradições e frustrações entre os geógrafos.

A relação entre a Geografia e Complexidade são construídas a partir de diversas leituras e diálogos possíveis, no entanto, há limites metodológicos e epistemológicos de aplicação de uma abordagem sistêmica, que permitiria uma maior interligação entre os diversos conceitos, proporcionando uma visão da emergência dos atributos, gerados através da interligação das partes que compõe o 'todo' e, que para a Geografia é o 
seu objeto de estudo: o espaço.

Para Suertegaray (2004) a leitura do conteúdo geográfico só pode ser lida como um campo multidisciplinar, ou seja, configura-se por uma multiplicidade de temas e problemas sendo operados. Entretanto, a análise do espaço geográfico só poderá ser decifrada através de um limite dos próprios conceitos operacionais do geógrafo. Porém, não basta esse limite, pois a complexidade é o princípio analítico que se busca para a compreensão aproximada da totalidade. Daí as práticas transdisciplinares².

Diante desse desafio, a abordagem interdisciplinar constitui uma prática que tem como objetivo a busca da compreensão/explicação de um problema formulado pelo conjunto. O trabalho interdisciplinar vai exigir um rompimento com os problemas específicos de cada campo, colocando na pauta das pesquisas questões de estruturação mais complexa. Além de exigir do pesquisador uma capacidade de interação e conhecimento transdisciplinar.

Assim, a complexidade que envolve o objeto de estudo geográfico, no ponto de vista de Leff (2004), ratifica como essa abordagem interdisciplinar pode se tornar uma alternativa de ruptura em relação a fragmentação. Nesse sentido, não é apenas uma proposta de desenvolvimento do conhecimento, mas elucidação dos nossos limites racionais e de articulação das ciências e, ao mesmo tempo, de crítica a ideia de interdisciplinaridade.

Neste aspecto, as limitações da metodologia interdisciplinar são produto de uma série de confusões criadas pela falta de unidade ou síntese em torno do que é interdisciplinaridade ou não. Primeiro, porque existe uma incerteza geral em relação ao significado desse termo. Além disso, há uma tendência persuasiva em associar o termo com uma prática individualizada dentro de cada disciplina, que eventualmente pode ser utilizado para resolver determinados problemas mais amplos.

Todavia, para Klein (1990), a dispersão no discurso é a causa fundamental para as confusões conceituais. Isso se dá, segundo a autora, pela falta de unidade nos trabalhos publicados sobre o assunto, embora esses textos tentem responder questões universais, são pensados como subdomínios disciplinares. Dessa forma, marginaliza-se intelectualmente e socialmente o discurso, dificultando a capacidade de reflexão sobre a natureza da interdisciplinaridade.

Portanto, ainda são vários caminhos perseguidos pela abordagem interdisciplinar: como um discurso teórico de vanguarda; como um conjunto de métodos para entender a complexidade do real; como crítica ao conhecimento fragmentado. O fato é que ao cruzar fronteiras epistemológicas, ao romper limites disciplinares, a metodologia interdisciplinar pode significar uma reestruturação do saber geográfico.

\section{CONCLUSÕES}

A consolidação da imagem de interdisciplinaridade aponta para uma saturação das estruturas acadêmicas segmentadas por uma tradição positivista de fazer ciência. Nesta direção, toda redefinição

2 Transdisciplinaridade significa, então, mais do que o horizonte que está além das disciplinas. Constitui a possibilidade de cada um colocar-se no lugar do outro, na busca da compreensão ampliada de sua disciplina. Neste sentido, a capacidade de transitar pelos diferentes campos é algo a ser buscado. 
curricular está ligada à complexidade e às mudanças da realidade social. Logo, é preciso reconhecer nos múltiplos olhares o consenso assumido na busca de compreensão/explicação do problema investigado

Tal contexto reaproxima as áreas de conhecimento científico, o que tende a ampliar os horizontes das ciências. Evidentemente, a Geografia precisa reavaliar determinados paradigmas que ainda são resquícios de uma herança secular, sob pena de criar uma crise epistemologia que, notadamente, pode diminuir o valor científico do saber geográfico nos próximos anos.

Ir além de suas fronteiras, no entanto, permanece um caminho cheio de percalços que precisam ser atravessados coletivamente. Porém, como nos desperta Santos (1996), os geógrafos também precisam dá sua parcela de corroboração neste processo de construção de uma nova epistemologia geográfica mais criativa e coerente com a realidade social que vivenciamos.

Gomes (2007) aponta que o caminho de constituição do fundamento epistemológico da ciência geográfica, sempre esteve integrado à dualidade de dois polos, físico e humano, clássico e moderno, presentes em todo processo de formação da disciplina. Contudo, como um domínio de saber científico abrangente a Geografia sempre foi um dos campos cujo estabelecimento precede a institucionalização da ciência moderna, revela-se um lócus privilegiado para discutir os limites da transposição metodológica interdisciplinar.

Desse modo, como especificado por Kunz (2016) a totalidade é complexa, logo as explicações dos fenômenos devem partir de uma abordagem interdisciplinar que promova a junção, bem como o confronto de conhecimentos especializados oriundos de diversas ciências, mas articulados pela categoria espaço geográfico. Em essência a Geografia é interdisciplinar, diante disso, o pensamento geográfico não pode se resumir a descrição clássica que resume a trajetória dos geógrafos, embora se reconheça que ela seja um passo importante para produzir explicações.

Enfim, a ideia de interdisciplinaridade nos parece um discurso científico pertinente aos interesses da Geografia, uma vez que se trata de um conhecimento que envolve diversos campos de visão. Portanto, parafraseando Maturana (2000) o que observamos depende dos instrumentos e dos mecanismos que utilizamos, nesta direção, apesar da ascendência de propostas modernas e pós-modernas e novas formas de transdisciplinaridades, a concepção interdisciplinar renasce como alternativa teórica e metodológica válida.

\section{REFERÊNCIAS}

BACHELARD, G.. A formação do espírito científico: contribuição para uma psicanálise do conhecimento. Rio de Janeiro: Contraponto, 1972.

BOURDIEU, P.; CHAMBOREDON, J. C.; PASSERON, J. C.. A profissão do sociólogo. Preliminares epistemológicas. Petrópolis: Vozes, 1999.

CLAVAL, P.. Do olhar do geógrafo a geografia como estudo do olhar dos outros. In: CONFERÊNCIA PROFERIDA NO SIMPÓSIO NACIONAL ESPAÇO E CULTURA, 4. Anais. Rio de Janeiro: UERJ, 2004.

COHEN, B. I.. Interactions. Some Contacts between the
Natural Science and the Social Sciences. The MIT Press, 1994.

DINIZ FILHO, L. L.. Certa má herança marxista: elementos para repensar a Geografia crítica. In: MENDONÇA, F.; KOZEL, S.. Epistemologia da Geografia Contemporânea. Curitiba: UFPR, 2004. p.77-109.

GERARDI, L. H.; HISSA, C. E.. Imagens da Geografia contemporânea: Modernidade, caos e intergração de sabers. In: GERARDI, L. H. O.; MENDES, I. A.. Teoria, técnica, espaços e atividades: temas de geografia contemporânea. São Carlos: UNESP, 2001. 
GOMES, P. C. C.. Geografia e Modernidade. Rio de Janeiro: Bertrand Brasil, 2007.

KLEIN, T. J.. Interdiciplinary: History, Theory \& Pratice. Detroit: Wayne State University Press, 1990.

KLEIN, J. T.. Crossing boundaries: knowledge, disciplinary, and interdisciplinary. Richmond: University Press of Virginia, 1996.

KUHN, T. S.. A Estrutura das Revoluções Científicas. São Paulo: Perspectiva, 1982.

KUNZ, S. A.. Espaço geográfico e interdisciplinaridade: Natureza do conhecimento geográfico no saber escolar. Revista Brasileira de Educação em Geografia, Campinas, v.6, n.12, p.53-73, 2016.

LEFF, E.. As Aventuras da Epistemologia ambiental: da articulação das ciências ao diálogo de saberes. Rio de Janeiro: Garamond, 2004.

MATTA, R.. Notas para uma pedagogia antropológica In: MATTA, R.. Um Mundo dividido: a estrutura social dos índios Apbuzyé. Petrópolis, Vozes, 1993.

MATURANA, H.. O que se observa depende do observador. In: THOMPSON, W. I.. Gaia: uma teoria do conhecimento.
São Paulo: 2000. p.61-76.

MORAES, A. C. R.. Geografia uma pequena história crítica. São Paulo: HUCITEC, 1997.

MOREIRA, R.. O que é Geografia. São Paulo: Brasiliense, 1998.

MORIN, E.. A Epistemologia da Complexidade. In: Introdução ao Pensamento Complexo. Lisboa: Insituto Piaget, 2002. p.137-174.

SANTOS, B. S.. Um discurso sobre as ciências na transição para uma ciência pós-moderna. Estudos Avançados, v.2, n.2, p.46-71, 1988.

SANTOS, M.. Por uma Geografia Nova: da crítica da Geografia a uma Geografia crítica. São Paulo: HUCITEC, 1996.

SOUZA, M. L.. O território: sobre espaço e poder, autonomia e desenvolvimento. In: CASTRO, I. et al. Geografia: Conceitos e Temas. Rio de Janeiro: Bertrand Brasil, 1995. p.77-116.

SUERTEGARAY, D. M. A.. Ambiência e pensamento complexo: ressignificação da geografia. In: SILVA, A. A. D.; GALENO, A.. Geografia: ciência do complexus: ensaios transdiciplinares. Porto Alegre: Sulina, 2004.

A CBPC - Companhia Brasileira de Produção Científica (CNPJ: 11.221.422/0001-03) detém os direitos materiais desta publicação. Os direitos referem-se à publicação do trabalho em qualquer parte do mundo, incluindo os direitos às renovações, expansões e disseminações da contribuição, bem como outros direitos subsidiários. Todos os trabalhos publicados eletronicamente poderão posteriormente ser publicados em coletâneas impressas sob coordenação da Sapientiae Publishing, da Companhia Brasileira de Produção Científica e seus parceiros autorizados. Os (as) autores (as) preservam os direitos autorais, mas não têm permissão para a publicação da contribuição em outro meio, impresso ou digital, em português ou em tradução. 